\title{
The regional integrated waste management concept in Slovenia
}

\author{
N. Samec ${ }^{1}$, F. Kokalj ${ }^{1,2}$ \& U. Kugonič ${ }^{2}$ \\ ${ }^{I}$ University of Mariboru, Faculty of Mechanical Engineering, Slovenia \\ ${ }^{2} \mathrm{KIV}$, Vransko, Slovenia
}

\begin{abstract}
The regional integrated waste management concept for municipal solid waste in Slovenia has been developed for about 200.000 people producing about 100,000 t/year of municipal solid waste. The technical part is based on law enforced separated collection, composting, recycling, mechanical biological treatment of residual waste, thermal treatment of the light fraction (LF) and disposal of the heavy fraction (HF). Great attention has been dedicated to the environmental benefits of the waste to energy plant role in the case of the thermal treatment of the mechanical biological treatment (MBT) prepared light fraction, which is shown in particular through the reduction of flue gas treatment residual amounts and bottom ash quality. Sewage sludge from the region is also induced into the process of thermal treatment. No special drying is foreseen; only the mechanical dewatering process is utilized to squeeze the water out to get the sewage to about $30 \%$ solids. The incineration ash and slag from the grate represent the major portion of solid residue and part of the investigation was for its application in concrete as a substitute for cement.
\end{abstract}

Keywords: integrated waste management, municipal solid waste, regional concept.

\section{Introduction}

The regional concept of integrated waste management in Slovenia includes:

- separate collection,

- $\quad$ sorting of separately collected fractions and recycling the marketable part, 
- composting of separately collected biodegradable fractions,

- mechanical biological treatment $(\mathrm{MBT})$ of the rest of the waste after separate collection,

- thermal treatment of the light fraction (LF) and waste residue from the sorting plant together with sewage sludge from the waste water treatment plant, and

- land filling of the biologically stable heavy fraction (HF) and the residue of thermal treatment.

The local, regional and national integrated waste management concept in Slovenia is composed of many closely related and connected technical and technological processes. With the aim of establishing environmentally and economically acceptable waste management it is essential for all the technological and logistical steps in the process of waste management to be interlinked and harmonised.

This paper will present the optimised Slovenian waste management strategy, also with regard to cost and environmental impact.

The concept of waste collection and treatment shown is coherent with the strategy of municipal waste management in the Republic of Slovenia, which is a part of the Waste Management Strategy for the Republic of Slovenia [2]. This document defines the priority list of waste management methods, based on European philosophy and directives:

- reduction of waste at the source,

- re-use and recycling of waste,

- $\quad$ energy recovery of waste, and

- land filling of the waste residue.

To reduce the waste amount in landfill, in accordance with the concept mentioned, waste must first be collected separately and then re-used or treated. In such a manner the amount of the waste residue to be deposited in landfill is minimised. The article shows many technical compliance arguments for the regional concept meeting the requirements, based on the structural and chemical analysis of municipal waste and foreseen technology for waste treatment.

The study involved the technical estimation of the single waste treatment technology and the influence on changing the quality and quantity of waste.

We have taken into account the sequence of waste treatment and changes in quantity and structure of waste in intermediate phases. The following technology was considered:

- $\quad$ aerobic treatment (composting),

- MBT, and

- thermal treatment.

Comparison is based on the complete sample analysis. At the end of the research estimation has been given on the extent of the possibility of controlling the waste flow in the region with the existing and planned technological equipment. 


\section{Integrated regional waste management system in Slovenia}

The legislation in Slovenia sets certain standards for the integrated waste management system. Based on those facts and international experience the basic model is tested firstly for technical and environmental feasibility, in accordance with local legislation, and at the last stage the cost comparison for local citizens is tested. The developed schematic model under consideration is shown in Figure 1.

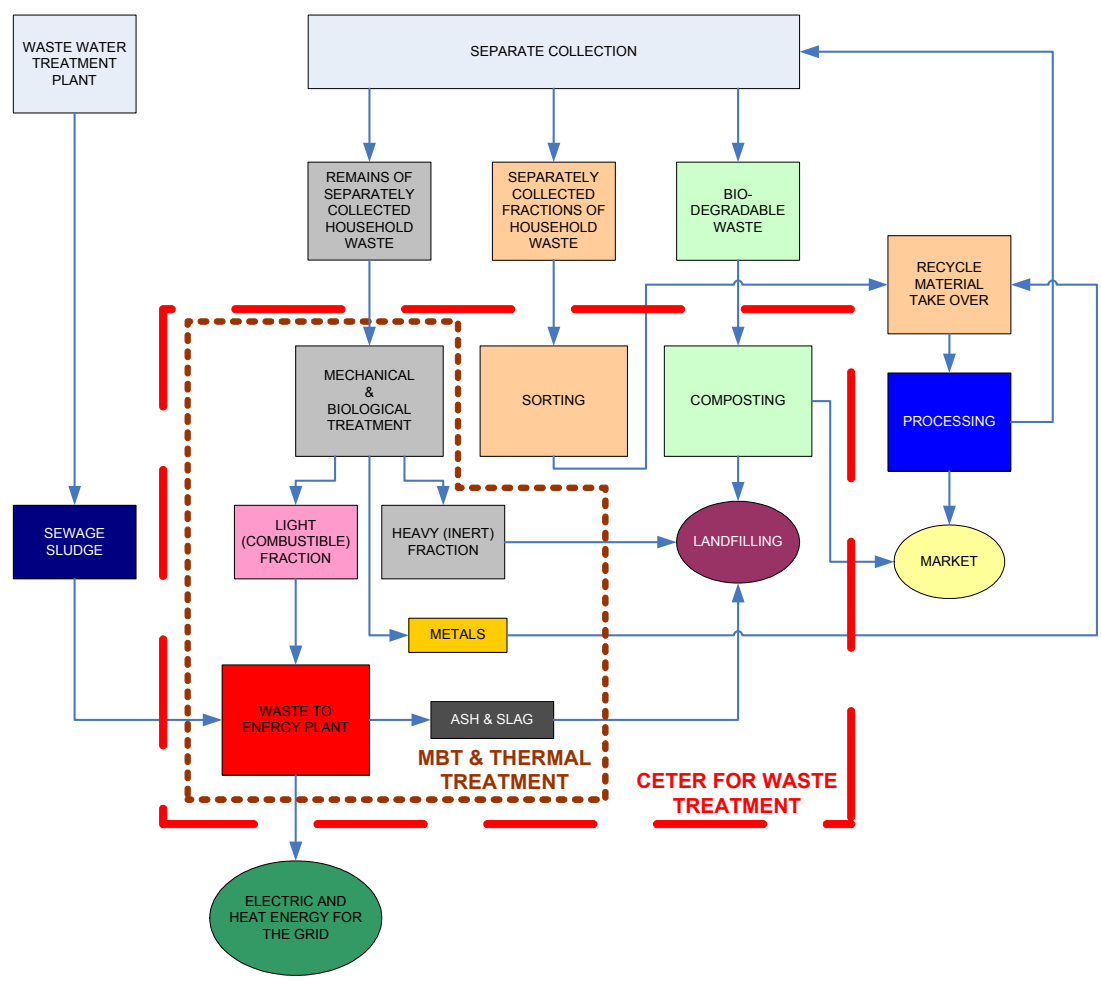

Figure 1: Scheme of the planned regional integrated waste management system.

The scheme represents material flow for the whole system. The technological processes are followed as described in Figure 1.

\subsection{Technology of aerobic treatment/composting}

The purpose of composting is treatment of the separately collected biodegradable fraction and treatment of the biodegradable part of bulky waste, which represents around $5-10 \%$ of the entire waste mass flow on a yearly bases in Slovenia [4]. When composting this sort of waste $30-40 \%$ of the mass is released in the form 
of water and carbon dioxide. The compost thus reaches a high enough quality to be able to sell it on the market without restrictions. Around $10 \%$ of this waste stream is waste residue and it is land filled fulfilling the strong regulations concerning total organic carbon involved.

When dealing with such a concept less attention should be focused on quantity than on the possible future changes in the structure of separately collected biodegradable waste. Basic conditions of waste structure and properties have to be fulfilled in order to attain satisfactory composting results through a favourable course of the process:

- well mixed homogenous material with suitable structure (air pore volume),

- optimal amount of oxygen ranging from 1 to 4 grams of oxygen per gram of organic substance,

- optimal moisture, ranging between 50-70\%. Below 50\% dry stabilization takes places; too much moisture obstructs the entrance of oxygen into the pores of organic material;

- the ratio between $\mathrm{C}$ and $\mathrm{N}$ defines composting velocity. Nitrogen is important in micro organisms' cell structure development; the lack of which causes stagnation in micro organisms' multiplication. The most favourable ratio for the incoming material is a $\mathrm{C} / \mathrm{N}$ ration of $20: 1$ to 40:1,

- $\quad \mathrm{pH}$ value must be around 7 .

The proposed model of compost mixture is based on the current structure of waste. The results are given in Table 1 .

Table 1: $\quad$ Physical and chemical characteristics of the mixture of waste being composted.

\begin{tabular}{|l|l|l|l|l|}
\hline Material & $\begin{array}{l}\text { Density } \\
{\left[\mathrm{t} / \mathrm{m}^{3}\right]}\end{array}$ & $\begin{array}{l}\text { Moisture } \\
{[\%]}\end{array}$ & $\begin{array}{l}\text { Nitrogen Content } \\
{[\% \text { dry matter }]}\end{array}$ & C:N ratio \\
\hline Sawdust & 0.320 & 30 & 0.10 & 600 \\
\hline Straw & 0.128 & 10 & 0.70 & 80 \\
\hline Cereal residues & 0.016 & 10 & 0.70 & 65 \\
\hline Compost - dry & 0.320 & 40 & 0.00 & 30 \\
\hline Organic residues from kitchen & 0.289 & 70 & 2.40 & 15 \\
\hline Paper (scraping) & 0.289 & 20 & 0.20 & 155 \\
\hline Chard board & 0.144 & 10 & 0.10 & 565 \\
\hline Garden waste & 0.192 & 45 & 1.80 & 40 \\
\hline Pruning of grass & 0.320 & 80 & 3.40 & 17 \\
\hline Leaves & 0.176 & 40 & 0.90 & 54 \\
\hline Residues from trees - pruning & 0.256 & 15 & 1.00 & 53 \\
\hline Residues from shrubs - pruning & 0.770 & 70 & 3.10 & 16 \\
\hline Paper pulp & 0.833 & 82 & 0.59 & 90 \\
\hline
\end{tabular}


Based on actual flow rates the mixture for composting is created. The moisture and $\mathrm{C} / \mathrm{N}$ ratio is easily controlled and corrected by means of additional composting material and watering or drying the mixture. The most important concern all the time should be good material aeration.

In case of an increase in quantity of waste with a high $\mathrm{C}: \mathrm{N}$ ratio, waste with a lower $\mathrm{C}: \mathrm{N}$ ratio has to be added for compensation. This is possible only in the case when adequate quantities of appropriate waste are available. In the case of a lack of waste with a low $\mathrm{C}: \mathrm{N}$ ratio, a part of the waste with a high $\mathrm{C}: \mathrm{N}$ ratio has to be excluded and temporarily stored, until sufficient quantities of all waste fractions are gathered. In this manner short term oscillations in the waste structure to be composted can be compensated for. In the case of higher deviations in the waste structure a disturbing part of waste has to be processed by a different technology.

The $\mathrm{C}: \mathrm{N}$ ratio of sawdust, paper and chard board and their amounts are decisively too high and it is not possible to compost them all. On the other hand this waste has relatively high caloric value and can be used as a fuel in heating plants. It can be used together with the light fraction from MBT until its composition is within the limits of parameters defined for heating plants.

\subsection{Mechanical and biological treatment technology}

Applying MBT the rest of the waste will be treated. This residue represents about $60 \%$ of the whole mass flow [4]. In Table 2 the average structure of waste at the entrance is shown. This data represents the input date to test system performance.

The average structure of the waste residue in Slovenia is similar to the structure of waste elsewhere in western European countries. Data for Germany [3], where partition to components somewhat differs from Slovenia is given in Table 3.

Table 2: $\quad$ Average structure of waste residue.

\begin{tabular}{|l|c|}
\hline Component & Share (\%) \\
\hline textile & 3 \\
\hline paper sum & 24 \\
\hline plastic sum & 18 \\
\hline wood & 1 \\
\hline metals & 4 \\
\hline building material - inorganics & 18 \\
\hline glass & 6 \\
\hline biological part & 25 \\
\hline other (styropor, rubber, Al - folium...) & 1 \\
\hline total & 100 \\
\hline
\end{tabular}


The primary task of mechanical and biological treatment is mechanical waste preparation and aerobic microbiologic waste treatment with the aim of biologically stabilizing waste and drying it. The mechanical separation of the combustible and incombustible parts of the waste follows.

The structure of the waste residue sample (Table 2) varies depending on season and weather conditions. It also depends on the contribution region (rural, urban...), which influences the moisture and biodegradable waste share.

A considerable decrease in amounts of municipal waste from commerce is expected due to the regulation on waste packaging material and the aim of lowering the costs in commerce in general.

At the same time an increase in the quantity of household waste is expected. The fact is that an increase in the gross domestic product and peoples' living standard is consequentially shown also as an increase in waste quantities.

Municipal solid waste can be divided into two fractions, the so called light fraction (LF) and heavy fraction (HF), as previously mentioned. LF has good combustion properties and a high calorific value thus it should be used for energy recovery in waste to energy plants (WEP). HF contains mainly inorganic matter with admixtures of biodegradable waste. It is reasonable to discard it in landfill after biological treatment.

Table 3: $\quad$ Average structure of waste in Germany [3].

\begin{tabular}{|l|c|}
\hline Components & Share (\%) \\
\hline paper sum & 25 \\
\hline plastic sum & 6 \\
\hline wood, rubber and textile & 5 \\
\hline moist biological part & 25 \\
\hline micro waste $(<8 \mathrm{~mm})$ & 15 \\
\hline inorganic material (metal, mineral inert material) & 20 \\
\hline inseparable residue & 4 \\
\hline total & 100 \\
\hline
\end{tabular}

\subsubsection{MBT process}

The MBT process includes the following stages:

- $\quad$ entry into the treatment,

- grinding,

- intermediate storage,

- biological treatment: bio-stabilization, bio-drying,

- mechanical treatment: metals and LF elimination

- HF discharge in land filling site.

The municipal solid waste is conveyed from the entry pit into the grinder by an automatic crane with grabber. The bio-stabilization device is a large and highly mechanized bioreactor. The grinded waste in dimensions from 200 to 300 $\mathrm{mm}$ is exposed to the bio-oxidation process and gradual drying. In our 
experience it is possible to reach $50-60 \%$ reduction in the biodegradable (organic) substance share in 12 to 15 days. The moisture is also reduced to $15 \%$ compared to the entering municipal waste (from 30 to $40 \%$ ).

The fraction intended for bio-stabilization is piled in 4-5 $\mathrm{m}$ thick layers by the bridge crane with the adapted grabber. The placed material remains in the hall for 10 to 14 days. The control and supervision of the aerobic biodegradation is enabled by the perforated hall floor providing a supply of air to the waste. Under the perforated floor there is a free air space, the so called plenum, which enables even distribution of air along the whole length of the aerated section. During the bio-stabilization process, $25 \%$ of the total weight is lost from the bulk of waste by water evaporation and $\mathrm{CO}_{2}$ production.

When the bio-stabilization process is finished, the material is transferred from the bio-stabilization site to the mechanical treatment site. After sieving, the combustible part of the LF is separated by the air separator. The separated LF is grinded. In the next step the metals (Iron, Aluminum) are separated out by the nonmagnetic/magnetic separator. The calorific value of the LF is between 15 and $20 \mathrm{MJ} / \mathrm{kg}$. The quantity of each of the fractions is given in Table 4.

Table 4: Quantity of each material after MBT.

\begin{tabular}{|l|c|}
\hline Material & Quantity [\%] \\
\hline water and $\mathrm{CO}_{2}$ & 30 \\
\hline inert fraction & 4 \\
\hline $\mathrm{HF}$ & 27 \\
\hline LF & 33 \\
\hline ferrous metals & 3 \\
\hline nonferrous metals & 3 \\
\hline
\end{tabular}

The HF should fulfill the landfill regulations regarding a TOC amount of $18 \%$ and a DOC of $2500 \mathrm{mg} / \mathrm{l}$. In our investigation it has been found that the mentioned conditions have been reached after successive sieving processes to exclude the reaming organic compounds. The results are given in Table 5.

Table 5: $\quad$ HF analysis regarding TOC and DOC.

\begin{tabular}{|l|l|l|}
\hline Parameter & \multicolumn{1}{|c|}{ Method } & Value \\
\hline dried residue $105^{\circ} \mathrm{C}$ in $\%$ & SIST EN 12880 & 76.33 \\
\hline burning residue $550^{\circ} \mathrm{C}$ in $\%$ & SIST EN 12879 & 57.94 \\
\hline TOC in \% d.m. & SIST EN 13137 & 14.68 \\
\hline DOC in mg/l & SIST EN 12457-4 & 936.5 \\
\hline
\end{tabular}

\subsection{Thermal treatment technology}

Thermal treatment rounds up the whole waste treatment sequence. The thermal treatment system in the form of WEP is planned for use of the entire amount of 
the LF and raw sewage sludge from the central waste water treatment plant. A two stage combustion system has been applied in the case of applied WEP.

\subsubsection{Chemical analysis of combustible fractions}

Preliminary treated municipal waste in the form of the LF from the MBT process, with a heating value between 15 and $20 \mathrm{MJ} / \mathrm{kg}$, and sludge from municipal waste water treatment plants with a maximal $30 \%$ share of dry solids, with a heating value from 0,35 to $3,5 \mathrm{MJ} / \mathrm{kg}$, enter the technological process of WEP. The LF is composed of the components that are listed in Table 6.

The average quantity of LF single components is represented in Table 7 . The average sewage sludge composition analysis is presented in Table 8.

\subsubsection{Combustion residues from WEP}

During combustion in WEP, the LF is reduced to about $90 \%$ by mass. The remains of combustion are mostly bottom ash (BA) and minor amounts of fly ash, boiler ash and flue gas treatment residue classified as hazardous waste. The BA composition and its amount from WEP fed by the LF differ drastically from

Table 6: $\quad$ LF components.

\begin{tabular}{|l|c|c|c|c|}
\hline & \multicolumn{4}{|c|}{ MATERIAL COMBUSTION PROPERTIES } \\
\hline & Moisture & Ash & Combustibles & Heating value \\
\hline combustible fraction & \multicolumn{4}{|c|}{$(\%)$} \\
\hline textile & 7.56 & 5.76 & 86.68 & 16.65 \\
\hline chart board & 6.85 & 11.88 & 81.27 & 17.49 \\
\hline soft paper & 23.99 & 12.43 & 63.58 & 10.1 \\
\hline plastic foil & 0.51 & 13.24 & 86.25 & 40.14 \\
\hline hard foil & 0.4 & 5.28 & 94.32 & 40.12 \\
\hline PET bottles & 0.42 & 0.15 & 99.43 & 21.51 \\
\hline wood & 12.52 & 2.31 & 85.17 & 16.32 \\
\hline styrophor & 1.07 & 9.98 & 88.95 & 27.95 \\
\hline
\end{tabular}

Table 7: $\quad$ The average composition of the LF in Slovenia.

\begin{tabular}{|l|c|}
\hline Fraction & Mass share [\%] \\
\hline textile & $12-16$ \\
\hline chard board & $10-15$ \\
\hline soft paper & $30-40$ \\
\hline plastic foil & $10-15$ \\
\hline hard plastic & $9-11$ \\
\hline PET bottles & $4-6$ \\
\hline wood & $2-4$ \\
\hline styrophor & $0.5-1.5$ \\
\hline
\end{tabular}


Table 8: The analysis results of sewage sludge from the central waste water treatment plant.

\begin{tabular}{|l|c|l|}
\hline Parameter & result & unit \\
\hline water content & $70-85$ & $\%$ \\
\hline bearing residue (ash) & $35-50$ & $\% *$ \\
\hline heating value & $9-16$ & $\mathrm{MJ} / \mathrm{kg} *$ \\
\hline nitrogen & $1-6$ & $\% *$ \\
\hline organic carbon & $20-25$ & $\%^{*}$ \\
\hline hydrogen & $3-4$ & $\% *$ \\
\hline oxygen & $25-45$ & $\%^{*}$ \\
\hline sulphur & $0.5-1.0$ & $\%^{*}$ \\
\hline chlorine & $0.1-0.3$ & $\%^{*}$ \\
\hline fluoride & $90-120$ & $\mathrm{mg} / \mathrm{kg}^{*}$ \\
\hline
\end{tabular}

* The results refer to contain of components in dry matter at $105^{\circ} \mathrm{C}$.

Table 9: $\quad$ Chemical composition of cement (CEM) and BA from WEP and MBGI.

\begin{tabular}{|c|c|c|c|}
\hline \multirow{2}{*}{ Oxide } & \multicolumn{3}{|c|}{ Content (wt. \%) } \\
\cline { 2 - 4 } & CEM & BA (WEP) & BA MBGI [1] \\
\hline $\mathrm{SiO}_{2}$ & 22.3 & 24 & $41.13-56.99$ \\
\hline $\mathrm{Al}_{2} \mathrm{O}_{3}$ & 5.83 & 14.8 & $9.2-11.35$ \\
\hline $\mathrm{Fe}_{2} \mathrm{O}_{3}$ & 2.17 & 2.7 & $3.97-8.61$ \\
\hline $\mathrm{CaO}$ & 60.81 & 39 & $13.22-19.77$ \\
\hline $\mathrm{MgO}$ & 2.82 & 1.7 & $3.46-3.85$ \\
\hline $\mathrm{Na}_{2} \mathrm{O}$ & 0.34 & 0.9 & $2.84-5.87$ \\
\hline $\mathrm{K}_{2} \mathrm{O}$ & 0.72 & 0.2 & $1.35-1.57$ \\
\hline $\mathrm{SO}_{3}$ & 2.75 & - & - \\
\hline
\end{tabular}

the BA of conventional mass burning grate incinerators (MBGI) fed by nontreated MSW [1]. It offers different possibilities for BA utilisation from WEP. Once of them can be the use of BA as a cement substitute in concrete production, based on similar BA composition and cement as shown in Table 9.

\section{Conclusion}

This paper has shown that a regional integrated waste management strategy can be utilized in cost and environmental benefits for the citizens of such closely populated regions.

The concept and technologies utilized in this concept are completely in accordance with European and national legislation and strategic waste 
management documents. Each technology applied is also a "Best available technology" for the segment considered.

The complete waste management system presented is based on separate collection. The separately collected waste fractions are more efficiently processed thus reducing investment and running costs.

The separately collected biodegradable fraction is composted. The product of this biological process is marketable, reducing landfill space and overall cost. The composting of biodegradable material also reduces the emission of greenhouse gases. The variation in composition concerning the $\mathrm{C}: \mathrm{N}$ ratio needs to be solved with temporary storage and the application of other technologies.

MBT is used for stabilization, drying and separation of combustible (high calorific) fractions and the inert (very low calorific) fraction. This enables overall better material conditions for WEP and land filling of inert material. Overall cost is again reduced due to reduced material quantities needing additional treatment.

The WEP is utilizing the energy in waste to produce heat and electric energy (CHP) for the citizens. This approach makes the CHP plant more acceptable to the society. Multi stage combustion and flue gas treatment devices make the WEP operate within legislative standards.

The remains of LF combustion - BA - involves the same significant components (i.e. $\mathrm{SiO}_{2}$ and $\mathrm{CaO}$ ) and in comparable amounts as cement. Therefore, the feasibility is to apply it in concrete as a cement supplement.

\section{References}

[1] Filipponi, P.; Polettini, A.; Pomi, R.; Sirini, P. Physical and mechanical properties of cement-based products containing incineration bottom ash; Waste Management. 2003, 23, 145-156.

[2] Ministry for the environment and spatial planning of the Republic of Slovenia, on-line data, www.mop.gov.si/en/legislation/environment/

[3] Sattler, K.; Emberger, J. Behandlung fester Abfaelle, 4. ueberarb. Aufl., Vogel Verlag und Druck KG, Wuerzburg, 1995.

[4] Statistical office of the Republic of Slovenia, on-line data, www.stat.si 